\title{
Avances con miras a la protección de los consumidores en el Mercosur
}

\section{POR LUCIANA BEATRIZ SCOTTI $(*)$}

(...) el crecimiento exponencial de las relaciones entre consumidores y profesionales, productores o proveedores de bienes y servicios en la región y las cambiantes modalidades en las que estas se producen, tornan necesario contar con un marco normativo claro que facilite la contratación internacional y estimule la confianza de las partes en los contratos internacionales de consumo. Preámbulo del Acuerdo del Mercosur sobre Derecho Aplicable en Materia de Contratos Internacionales de Consumo. Brasilia, 2017.

\begin{abstract}
Sumario: I. Introducción.- II. Panorama normativo en el ámbito internacional.- III. La situación en el Mercosur.- IV. Las normas Mercosur en la materia.- V. A modo de colofón.- VI. Bibliografía.
\end{abstract}

Resumen: a fin de remediar la desigualdad de las partes en las relaciones de consumo, los legisladores nacionales se han ocupado de dictar leyes protectorias que procuran hallar un cierto equilibrio negocial entre los contratantes. Sin embargo, en estos tiempos posmodernos, la protección de los consumidores ha dejado de ser un objetivo exclusivamente nacional. En la actualidad, las respuestas jurídicas para las relaciones de consumo transfronterizas deben provenir de los ámbitos regionales e internacionales. En particular, en un proceso de integración regional, como el Mercosur, que propende la libre circulación de bienes, servicios, personas y capitales, se torna ineludible adoptar acciones concretas para la protección de los consumidores y usuarios que entablan relaciones jurídicas en nuestra región. Entre dichas iniciativas, recientemente el Consejo Mercado

(*) Abogada (Medalla de Oro, Universidad de Buenos Aires, UBA). Magister en Relaciones Internacionales Universidad de Buenos Aires, UBA. Dra. de la Universidad de Buenos Aires, Área Derecho Internacional. Diploma de Posdoctorado, Facultad de Derecho, Universidad de Buenos Aires, UBA. Prof. Derecho Internacional Privado y Derecho de la Integración, Facultad de Derecho, Universidad de Buenos Aires, UBA. Investigadora Categoría I, (Ministerio de Educación). Miembro Permanente del Instituto de Investigaciones “Dr. Ambrosio L. Gioja”. Directora de Proyectos UBACyT. 
Común (CMC) ha aprobado el Acuerdo sobre derecho aplicable en materia de contratos internacionales de consumo.

Palabras claves: relaciones internacionales de consumo - integración regional - Mercosur - derecho internacional privado

\section{Avances en vue de la protection des consommateurs du Mercosur}

Résumé: afin de remédier à l'inégalité des parties dans les relations de consommation, les législateurs nationaux ont pris soin de dicter des lois protectrices visant à trouver un certain équilibre de négociation entre les parties contractantes. Cependant, en ces temps postmodernes, la protection des consommateurs a cessé d'être un objectif exclusivement national. Actuellement, les réponses juridiques aux relations de consommation transfrontalières doivent provenir des sphères régionales et internationales. En particulier, dans un processus d'intégration régionale tel que le Mercosur, favorisant la libre circulation des biens, des services, des personnes et des capitaux, il devient inévitable d'adopter des actions concrètes pour la protection des consommateurs et des utilisateurs qui établissent des relations juridiques dans notre région. Parmi ces initiatives, le Conseil du marché commun (CMC) a récemment approuvé l'Accord sur le droit applicable aux contrats internationaux de consommation.

Mots clés: relations internationales de consommation - intégration régionale Mercosur - droit international privé

\section{Introducción}

A fin de remediar la desigualdad de las partes en las relaciones de consumo, los legisladores nacionales se han ocupado de dictar leyes protectorias que procuran hallar un cierto equilibrio negocial entre los contratantes.

En estos tiempos posmodernos, la protección de los consumidores ha dejado de ser un objetivo exclusivamente nacional. Actualmente, la realidad es otra, tal como describe la Profesora Lima Marques (2001, p. 2):

Con la apertura de los mercados a productos y servicios extranjeros, con la creciente integración económica, la regionalización del comercio, las facilidades del transporte, el turismo masivo, el crecimiento de las telecomunicaciones, de la conexión en red de computadoras, del comercio electrónico, es imposible negar que el consumo ya sobrepasa las fronteras nacionales. Los bienes extranjeros están en los supermercados, los servicios son ofrecidos por proveedores con sede en el exterior, a través del telemarketing, de la televisión, la radio, la 
internet, la publicidad de masas cotidiana para la mayoría de los ciudadanos de nuestras metrópolis regionales. Ya no es necesario viajar, ser un consumidor activo, un consumidor turista, ni trasladarse para ser consumidor, "contratando en forma internacional o relacionándose con proveedores de otros países". En definitiva, "consumir en forma internacional es típico de nuestra época".

En efecto, la autora destaca que no hay nada más posmoderno que las relaciones virtuales, desmaterializadas, que involucran a una pluralidad de agentes, típicas de la sociedad de la información, fluidas, rápidas, visuales, interactivas, simultáneas, despersonalizadas, y, a su vez, globalizadas y culturalmente niveladas, atemporales, internacionales, desterritorializadas, típicas de la economía pos-fordista, de servicio, de hacer, de lo inmaterial, lo desregulado, lo tercerizado, lo individual (Lima Marques, 2004).

Así, la protección del consumidor se inserta en este contexto como válvula de escape de los conflictos posmodernos, pues representa jurídicamente la garantía de una norma mínima de seguridad y adecuación de los servicios y productos, nacionales o importados, comercializados en los mercados abiertos de hoy (Jayme, 1995).

Ante estos escenarios, las respuestas jurídicas para las relaciones de consumo transfronterizas deben provenir de los ámbitos regionales e internacionales. En particular, en un proceso de integración regional, como el Mercosur, que propende la libre circulación de bienes, servicios, personas y capitales, se torna ineludible adoptar acciones concretas para la protección de los consumidores y usuarios que entablan relaciones jurídicas en nuestra región.

Desde sus orígenes nuestro espacio integrado se ha ocupado del resguardo de los derechos de tales sujetos más vulnerables y recientemente, en diciembre de 2017, el Consejo Mercado Común (CMC) ha aprobado el Acuerdo sobre derecho aplicable en materia de contratos internacionales de consumo.

En este trabajo nos ocuparemos de las diferentes normas Mercosur sobre la materia que nos convoca, así como la fuente interna de los Estados partes, y en particular analizaremos el mencionado Acuerdo.

\section{Panorama normativo en el ámbito internacional}

En el ámbito convencional, ya sea internacional o regional, en materia contractual, respecto de ley aplicable o de la jurisdicción, encontramos diversos instrumentos que, sin embargo, suelen no regular o directamente excluyen de su ámbito de aplicación a los contratos celebrados con consumidores. 
Así, los Tratados de Derecho Civil Internacional de Montevideo de 1889 y los de 1940 regulan la jurisdicción competente, así como la ley aplicable en materia contractual utilizando los criterios clásicos, sin hacer ninguna alusión específica a los contratos de consumo (1).

La Convención de las Naciones Unidas sobre los Contratos de Compraventa Internacional de Mercaderías, concluida en Viena en 1980 (2), en su artículo 2 establece que no se aplicará a las compraventas de mercaderías compradas para uso personal, familiar o doméstico, salvo que el vendedor, en cualquier momento antes de la celebración del contrato o en el momento de su celebración, no hubiera tenido ni debiera haber tenido conocimiento de que las mercaderías se compraban para ese uso. En similares términos, se expide el artículo 2 de la Convención sobre la Ley Aplicable a la Compraventa Internacional de Mercaderías (no vigente) suscripta en la ciudad de La Haya el 30 de octubre de 1985.

Al respecto, Garro y Zuppi (1990, p. 81) afirman que la razón principal de excluir la venta a consumidores del ámbito de aplicación ha sido la de evitar un eventual conflicto entre las normas de la Convención y las leyes de orden público de protección al consumidor.

Por su parte, la CIDIP V sobre Derecho Aplicable a los Contratos Internacionales de 1994 (en vigor solamente entre México y Venezuela), a diferencia de la Convención de Roma de 1980 de la Unión Europea (sustituida por el Reglamento (CE) No 593/2008 sobre la ley aplicable a las obligaciones contractuales - Roma I-) no previó ninguna norma especial para el contrato de consumo internacional. Además, las conexiones flexibles elegidas y la amplitud con que es receptada la autonomía de la voluntad se adecuan a las relaciones entre comerciantes internacionales, más no a las contraídas con consumidores.

Por su parte, la Convención de las Naciones Unidas sobre la Utilización de las Comunicaciones Electrónicas en los Contratos Internacionales(3) también excluye de su ámbito de aplicación a los contratos concluidos con fines personales, familiares o domésticos (artículo 2.a). En la nota explicativa de la Secretaría de UNCITRAL aclara que a diferencia de la exclusión en el mismo sentido que establece el artículo 2 a) de la Convención de Viena de 1980, la exclusión de este tipo de operaciones en el marco de la Convención sobre Comunicaciones Electróni-

(1) Argentina, Paraguay y Uruguay se encuentran vinculados por los Tratados de Montevideo de 1940. Brasil y Venezuela no integran esta obra codificadora. En cambio, son partes del Código de Bustamante y Sirvén que tampoco regula los contratos internacionales de consumo.

(2) Se encuentra en vigor entre 89 Estados, entre ellos Argentina, Brasil, Paraguay y Uruguay.

(3) Se encuentra en vigor entre 11 países del Mercosur, solamente la República del Paraguay ratificó esta convención. 
cas es absoluta, lo cual significa que no será aplicable a los contratos celebrados con fines personales, familiares o domésticos, aun cuando esa finalidad no resulte evidente para la otra parte.

En consecuencia, observamos que muy pocas organizaciones y foros de codificación internacional se han ocupado del tema, por el contrario, tienden a excluirlo.

Tal como observa Lima Marques (2001, p. 4):

(...) las normas nacionales, reguladoras del comercio internacional y el derecho uniforme del comercio internacional o la denominada lex mercatoria, en general no se preocupan de proteger al consumidor y, al contrario, tratan de excluir estos contratos de su campo de aplicación.

No podemos soslayar, sin embargo, que en el marco de las negociaciones de la CIDIP VII algunos de los Estados miembros de la OEA han realizado interesantes propuestas: la delegación de Brasil presentó una propuesta de Convención Interamericana sobre la Ley Aplicable a algunos Contratos y Relaciones de Consumo (4); la delegación de los Estados Unidos presentó un esquema para una Ley Modelo sobre Mecanismos de Restitución Monetaria para Consumidores; y la delegación de Canadá presentó un informe sobre la Jurisdicción y la Protección al Consumidor en el Comercio Electrónico.

En particular, el proyecto de Convención Interamericana de Derecho Internacional Privado sobre la ley aplicable a algunos contratos y relaciones de consumo elaborado por la Profesora Claudia Lima Marques, en su artículo 2 dispone que

1. Los contratos y las transacciones realizadas en las que participen consumidores, especialmente los contratos celebrados a distancia, por medios electrónicos, de telecomunicaciones o por teléfono, encontrándose el consumidor en el país de su domicilio, serán regidos por la ley de ese país o por la ley que fuera más favorable al consumidor, a elección de las partes, sea la ley del lugar de celebración del contrato, la ley del lugar de ejecución, de la prestación más característica, o la ley del domicilio o sede del proveedor de los productos o servicios.

2. Los contratos celebrados por el consumidor estando fuera del país en el cual se domicilia se regirán por la ley que resulte elegida por las

(4) En 2010, a fin de simplificar la propuesta de Convención, las delegaciones de los gobiernos de Brasil, Argentina y Paraguay, reunidas en Buenos Aires, sistematizaron la versión final de la propuesta brasileña presentada en la OEA, creando una versión simplificada denominada "Propuesta Buenos Aires". 
partes, quienes podrán optar por la ley del lugar de celebración del contrato, la ley del lugar de ejecución o la del domicilio del consumidor.

Por su parte, en la Unión Europea, el artículo 6 del Reglamento (CE) № 593 sobre la Ley aplicable a las obligaciones contractuales (Roma I) dispone que el contrato celebrado por una persona física para un uso que pueda considerarse ajeno a su actividad comercial o profesional ("el consumidor") con otra persona ("el profesional") que actúe en ejercicio de su actividad comercial o profesional, se regirá por la ley del país en que el consumidor tenga su residencia habitual, siempre que el profesional: a) ejerza sus actividades comerciales o profesionales en el país donde el consumidor tenga su residencia habitual, o b) por cualquier medio dirija estas actividades a ese país o a distintos países, incluido ese país, y el contrato estuviera comprendido en el ámbito de dichas actividades.

Debemos también señalar que la Conferencia de La Haya ha incorporado en su agenda la Propuesta de Brasil de un borrador de convención sobre cooperación y acceso a la justicia de los turistas internacionales, que en definitiva son un tipo especial de usuario-consumidor(5).

Finalmente, encontramos normas de soft law, no vinculantes, relativas a la protección de los consumidores.

Por ejemplo, la Declaración de Sofía sobre los Principios Internacionales de Protección al Consumidor fruto de la septuagésima quinta Conferencia de la Asociación de Derecho Internacional celebrada en la ciudad de Sofía, Bulgaria, del 26 al 30 de agosto de 2012. El Comité para la Protección Internacional de los Consumidores de dicha asociación, por resolución No 4/2012, estableció los siguientes principios guía: 1) Principio de la vulnerabilidad; 2) El Principio de protección más favorable al consumidor; 3) Principio de justicia contractual; 4) Principio de crédito responsable; 5) Principio de participación de las asociaciones de consumidores.

Por otro lado, son de significativa importancia las Directrices de las Naciones Unidas para la Protección del Consumidor aprobadas por la Asamblea General en su resolución 39/248, de 16 de abril de 1985, ampliadas posteriormente por el Consejo Económico y Social en su resolución 1999/7, de 26 de julio de 1999, y revisadas y aprobadas por la Asamblea General en su resolución 70/186, de 22 de diciembre de 2015. Las Directrices se aplican a las transacciones entre empresas y consumidores, incluida la provisión de bienes y servicios a consumidores por empresas estatales. Comprenden un conjunto valioso de principios que establecen las principales características que deben tener las leyes de protección del

(5) Puede ampliarse en: https://www.hcch.net/es/projects/legislative-projects/protection-oftourists [Fecha de consulta: 16/02/2019]. 
consumidor, las instituciones encargadas de aplicarlas y los sistemas de compensación para que sean eficaces.

Los principios que establecen los parámetros de unas buenas prácticas comerciales en las actividades comerciales en línea y fuera de línea con los consumidores son los siguientes: 1) Trato justo y equitativo; 2) Conducta comercial; 3) Divulgación y transparencia; 4) Educación y sensibilización; 5) Protección de la privacidad; 6) Mecanismos de reclamación de los consumidores que les permitan resolver controversias de manera rápida, justa, transparente, poco costosa, accesible y efectiva sin cargas ni costos innecesarios.

Las Directrices también contribuyen a promover la cooperación internacional entre los Estados miembros en el ámbito de la aplicación y alientan a que se compartan las experiencias en materia de protección de los consumidores. En este sentido, los Estados miembros deben especialmente en un contexto regional o subregional cooperar o alentar la cooperación en la aplicación de las políticas de protección del consumidor para conseguir mejores resultados en el marco de los recursos existentes. Además, tanto los Estados como sus organismos encargados de hacer efectiva la protección del consumidor deben aprovechar las redes internacionales existentes y concertar arreglos bilaterales y multilaterales pertinentes y otras iniciativas para aplicar las presentes directrices (6).

En línea con estas ideas, el Mercosur, en su carácter de proceso de integración subregional, tal como adelantamos, ha venido trabajando prácticamente desde sus orígenes en la protección de los consumidores y usuarios que operan en nuestro espacio.

\section{La situación en el Mercosur}

\section{III.1. Las legislaciones internas de los Estados partes}

Respecto del derecho interno de los Estados miembros del Mercosur, nos encontramos con la Ley de Defensa del Consumidor de Argentina (24.240/93 y modificatorias), y el Título III sobre "Contratos de Consumo" del Libro Tercero del Código Civil y Comercial de la Nación (artículos 1092 a 1122); el Código de Defensa del Consumidor de Brasil (8.078/90 y modificatorias); la Ley Paraguaya de Defensa del Consumidor y del Usuario (1.334/98), y la Ley Uruguaya de Defensa

(6) Las Directrices de las Naciones Unidas para la Protección del Consumidor se encuentran disponibles en: https://unctad.org/es/PublicationsLibrary/ditccplpmisc2016d1_es.pdf [Fecha de consulta: 16/02/2019]. 
del Consumidor (17.250/00). En tanto, Venezuela no cuenta actualmente con una ley especial en la materia.

Sin embargo, tanto nuestra ley como la de los restantes países de la región tienen por finalidad, en general, proteger al consumidor en casos nacionales, que no presentan ningún elemento extranjero.

Así lo señala la doctrina especializada: "los Estados partes del Mercosur cuentan con leyes internas de protección al consumidor, pero su aplicación a casos internacionales lejos de una aceptación pacífica plantea innumerables discusiones" (Dreyzin de Klor, 2014, p. 28).

A continuación, detallaremos con más precisión las normas de fuente interna de los Estados parte del Mercosur, focalizando nuestro análisis en aquellas que, cuando las hubiera, se aplican a las relaciones de consumo transfronterizas.

\section{a) Argentina}

La República Argentina garantiza los derechos de los consumidores y usuarios de bienes y servicios en el artículo 42 de la Constitución Nacional.

De rango infraconstitucional, las principales disposiciones en la materia se encuentran en la Ley No 24.240 de Defensa del Consumidor, del 22 de septiembre de 1993, modificada por la ley No 26.361 del 12 de marzo de 2008. A su turno, en Código Civil y Comercial de la Nación (CCiv. y Com.), el Título III del Libro Tercero (Derechos personales) se ocupa también de los contratos de consumo.

Finalmente cabe destacar la ley No 26.993, del 7 de septiembre de 2014, que crea el servicio de conciliación previa en las relaciones de consumo y creación de la justicia nacional en esta materia.

Sin embargo, ninguna de las disposiciones mencionadas aborda a las relaciones transfronterizas de consumo.

En efecto, como bien señala Dreyzin de Klor (2014, p. 24):

(...) la Ley de Defensa del Consumidor (LDC) in totum resulta aplicable en principio solo a casos nacionales y que no corresponde valerse de sus disposiciones, o en todo caso hacerlas funcionar como normas de policía aplicables también respecto de casos con elementos extranjeros, los cuales deberán regirse por el derecho que resulte aplicable a consecuencia del funcionamiento de las normas de conflicto de DIPr (...). En consecuencia, la LDC en bloque solo se aplica en la medida en 
que el contrato se encuentre regido por el derecho de fondo argentino, lo cual no quita que, por una parte, de algunas de sus disposiciones puedan inferirse principios de orden público internacional y que por lo tanto operen como límites a la aplicación del derecho extranjero eventualmente aplicable, o bien que, aun cuando la relación se encuentre regida por un derecho extranjero, alguno de sus aspectos pueda quedar captado por el derecho argentino (podrían ser las cuestiones procesales).

Ahora bien, desde la vigencia del Código Civil y Comercial, contamos con la Sección 12a del Título IV del Libro Sexto (artículos 2654 y 2655), que, por primera vez en el derecho argentino, incorpora reglas sobre contratos internacionales de consumo.

De las dos disposiciones que integran la Sección, la primera se ocupa de establecer el juez competente para las relaciones de consumo, mientras que la segunda determina el derecho aplicable a los contratos de consumo. Las analizaremos brevemente a continuación.

El artículo 2654 CCiv. y Com. veda a las partes de una relación de consumo la posibilidad de celebrar un acuerdo de elección de foro y en consecuencia determina para distintos supuestos, los criterios atributivos de jurisdicción internacional (7).

Estos foros concurrentes, ante los que el consumidor, como parte actora, puede entablar una demanda son: 1) los jueces del lugar de celebración del contrato, 2) los del lugar del cumplimiento de la prestación del servicio, 3) los de lugar de la entrega de bienes, 4) los del lugar del cumplimiento de la obligación de garantía, 5) los del domicilio del demandado o 6) los del lugar donde el consumidor realiza actos necesarios para la celebración del contrato.

En consonancia con lo dispuesto en el artículo 2650 inciso c) también son competentes los jueces del Estado donde el demandado tiene sucursal, agencia o cualquier forma de representación comercial, cuando estas hayan intervenido en la celebración del contrato o cuando el demandado las haya mencionado a los efectos del cumplimiento de una garantía contractual.

En el caso que la demanda sea entablada contra el consumidor, la otra parte contratante, es decir, el proveedor, solo puede interponerla ante los jueces del

(7) En las XXVI Jornadas Nacionales de Derecho Civil, la Comisión 11 de Derecho Internacional Privado sobre consumidor internacional (La Plata, 28, 29 y 30 de septiembre de 2017) propuso de lege ferenda que cabría examinar la posibilidad de los acuerdos de elección de foro como cláusula asimétrica favorable al consumidor, es decir, en la medida que le permita plantear su demanda ante tribunales distintos de los indicados en el artículo 2654 del CCiv. y Com. 
Estado del domicilio del consumidor. Es de toda lógica esta solución que se limita a reiterar el principio general del artículo 2608 CCiv. y Com. según el cual siempre es competente el juez del domicilio o residencia habitual del demandado en las acciones personales.

Sorprendentemente, el artículo 2654 CCiv. y Com. no habilita al consumidor a demandar a su contraparte ante los jueces del lugar de su residencia habitual o domicilio, como contempla la regla general del Protocolo de Santa María sobre Jurisdicción Internacional en Materia de Relaciones de Consumo (no vigente), sobre el que volveremos, ni siquiera bajo las condiciones que exige el Reglamento (UE) No 1215/2012 relativo a la competencia judicial, el reconocimiento y la ejecución de resoluciones judiciales en materia civil y mercantil (en el caso del llamado "consumidor pasivo").

Sin embargo, es altamente probable que alguno de los múltiples foros expresamente previstos por la norma, coincida con el domicilio o residencia habitual del consumidor, y, por ende, se consagre indirectamente el foro protectorio. Por otro lado, si se configuran las excepcionales condiciones previstas en el artículo 2602 CCiv. y Com., el domicilio del consumidor podría convertirse en un foro de necesidad.

El derecho argentino también veda el ejercicio de la autonomía de la voluntad en materia de derecho aplicable, tal como dispone la última parte del artículo 2651 CCiv. y Com.

El artículo 2655, a diferencia del artículo anterior en materia de jurisdicción, diferencia entre "consumidor pasivo" y "consumidor activo", a los fines de determinar la ley aplicable.

En tal sentido, sigue con algunas diferencias, las reglas del reglamento 593/2008 del Parlamento Europeo y del Consejo, de 17 junio 2008, sobre la ley aplicable a las obligaciones contractuales (Reglamento Roma I).

Entonces, el artículo 2655 CCiv. y Com. diferencia dos supuestos. Si se dan una de las siguientes condiciones, los contratos de consumo se rigen por el derecho del Estado del domicilio del consumidor: a) si la conclusión del contrato fue precedida de una oferta o de una publicidad o actividad realizada en el Estado del domicilio del consumidor y este ha cumplido en él los actos necesarios para la conclusión del contrato (se ha mantenido esta exigencia, eliminada por el Reglamento de la UE, por ende, no se adecúa razonablemente a la contratación a distancia celebrada a través de medios electrónicos); b) si el proveedor ha recibido el pedido en el Estado del domicilio del consumidor; c) si el consumidor fue inducido por su proveedor a desplazarse a un Estado extranjero a los fines de efectuar 
en él su pedido; o d) si los contratos de viaje, por un precio global, comprenden prestaciones combinadas de transporte y alojamiento.

Si no se configuran esas condiciones, los contratos de consumo se rigen por el derecho del país del lugar de cumplimiento (consumidor activo). En caso de no poder determinarse el lugar de cumplimiento, el contrato se rige por el derecho del lugar de celebración. Es decir, ante la ausencia de las mencionadas circunstancias, se siguen las reglas para la determinación de la ley aplicable a los contratos en general en ausencia de elección de ley aplicable (artículo 2652).

En efecto, en las XXVI Jornadas Nacionales de Derecho Civil, la Comisión 11 de Derecho Internacional Privado sobre consumidor internacional (La Plata, 28, 29 y 30 de septiembre de 2017) propuso que la calificación autónoma del lugar de cumplimiento prevista en el artículo 2652 del CCiv. y Com., resulta de aplicación a los contratos de consumo en materia de derecho aplicable.

Un sector especializado de la doctrina, con el que coincidimos, ha criticado la redacción final del artículo 2655:

(...) antes de la aprobación del texto definitivo (...) fue insertada una modificación, sugerida por la Comisión Bicameral a fines del 2013, que condujo a que la ley aprobada contemplase un verdadero retroceso en materia de derecho aplicable a los contratos internacionales de consumo, al determinar que cuando el asunto no pueda encajarse en ninguno de los cuatro requisitos antes referidos, los contratos dejarán de ser regidos por el derecho del domicilio del consumidor, y pasarán a ser disciplinados por el derecho del lugar de cumplimiento, y cuando fuese imposible determinar dónde se dio la ejecución contrato, por el derecho del lugar de su celebración (...). [L]ugar de cumplimiento y lugar de celebración son puntos de conexión clásicos (...) que no ofrecen medida de protección a la parte débil de la relación de consumo, salvada la hipótesis en la cual coincidan con el lugar donde esté domiciliado el consumidor (Klein Vieira, 2017, p. 247).

En relación con esta disposición, la doctrina también ha expresado con acierto:

Si bien la norma en principio protege al consumidor pasivo, podríamos preguntarnos si, tal vez, no hubiese sido conveniente la adopción de una norma de conflicto materialmente orientada en su protección, de modo tal de dar la posibilidad de que tenga cabida un sistema jurídico que, no siendo el del domicilio del consumidor, pudiere resultar más favorable a sus intereses (...). Por otro lado, la consecuencia de excluir a los contratos de consumo de la posibilidad de ejercicio de la au- 
tonomía de la voluntad podría traer como consecuencia la aplicación de un derecho menos favorable para el consumidor (Iud, 2015, p. 227).

En similar sentido, se expidió la Asociación Argentina de Derecho Internacional (AADI) en una de sus conclusiones en oportunidad del XXVII Congreso Argentino AADI (Puerto Madryn, septiembre de 2015): "11. Hacer hincapié en la regulación de los contratos de consumo internacionales como contratos con parte débil, sin perjuicio de considerar que la protección es insuficiente y que hubiera sido deseable incluir una norma materialmente orientada a favor del consumidor" (8).

Por último, cabe poner de relieve que, en materia de protección del consumidor, juega un rol muy preponderante los principios de orden público internacional, así como las normas de aplicación inmediata, previstas con alcance general en los artículos 2599 y 2600 del CCiv. y Com. respectivamente.

Muchos de los principios fundamentales que integran el orden público internacional y de las normas internacionalmente imperativas se encuentran plasmados en el Código.

En este sentido, el artículo 1094 CCiv. y Com. menciona el principio de protección del consumidor y el de acceso al consumo sustentable.

El artículo 1095 dispone que el contrato de consumo se interpreta en el sentido más favorable para el consumidor. Cuando existen dudas sobre los alcances de su obligación, se adopta la que sea menos gravosa.

A su turno, el artículo 1097 CCiv. y Com. consagra el principio de trato digno, en tanto que el artículo 1098 establece el principio de trato equitativo y no discriminatorio.

Asimismo, el artículo 1099 reconoce el principio de libertad de contratar, con motivo del cual están prohibidas las prácticas que limitan la libertad de contratar del consumidor, en especial, las que subordinan la provisión de productos o servicios a la adquisición simultánea de otros, y otras similares que persigan el mismo objetivo.

Por otro lado, las disposiciones sobre cláusulas abusivas, es decir, aquellas que habiendo sido o no negociadas individualmente, tienen por objeto o por efecto provocar un desequilibrio significativo entre los derechos y las obligaciones de las partes, en perjuicio del consumidor (artículos 1119 y ss.), y que, por tal razón, se

(8) Las conclusiones están disponibles en: http://www.aadi.org.ar/index.php?acc=4 [Fecha de consulta: 16/02/2019]. 
tiene por no convenidas, bien pueden considerarse normas internacionalmente imperativas.

\section{b) Brasil}

La Constitución de la República Federativa de Brasil, de 1988, reconoce a la defensa del consumidor como un derecho fundamental (artículo 5). Además, entre otras previsiones, destaca el artículo 48 de las Disposiciones Constitucionales Transitorias que encomienda al Congreso la sanción de un Código de Defensa del Consumidor.

En tal sentido, el 11 de septiembre de 1990, el Poder Legislativo sancionó la ley No 8.078 que

Se constituye en un micro sistema normativo independiente, coherente y armónico, con reglas propias y especiales para las relaciones de consumo establecidas de modo contractual, precontractual o extracontractual, que involucran la adquisición y/o uso de productos y servicios (Klein Vieira, 2017, p. 221).

Sin embargo, dicho Código no contiene disposiciones de Derecho Internacional Privado para las relaciones y los contratos internacionales de consumo.

No obstante ello, de acuerdo con la Ley de Introducción a las Normas del Derecho Brasileño, se deduce que, a falta de norma especial, los contratos internacionales de consumo celebrados en Brasil, por contratantes nacionales o extranjeros, se rigen por el derecho brasileño. En tanto que aquellos celebrados en el exterior, se someterán al respectivo derecho extranjero.

A su turno, en materia de jurisdicción, el artículo 22 inc. II del Código de Proceso Civil, aprobado el 16 de marzo de 2015 por ley No 13.105 establece la jurisdicción de los jueces brasileños cuando el consumidor tiene domicilio o residencia en Brasil.

\section{c) Paraguay}

Por su parte, la Constitución de la República de Paraguay, de 1992, se refiere en varias disposiciones a la protección de los consumidores (artículos 27, 28, 38, 72).

A su turno, desde el 27 de octubre de 1998, Paraguay cuenta con la Ley de Defensa del Consumidor y del Usuario (ley No 1.334) y desde el 2 de mayo de 2003, con un sistema de conciliación, mediación y resolución de sumarios administrativos en materia de defensa del consumidor (decreto No 21.004). Además, la ley 
№ 4.868, del 26 de febrero de 2013 regula el comercio y la contratación realizados por medios electrónicos entre proveedores de bienes y servicios, intermediarios, y los consumidores y usuarios.

Sin embargo, ninguna de estas normas se ocupa de las relaciones transfronterizas (9).

\section{d) Uruguay}

A diferencia de sus socios, la República Oriental del Uruguay no cuenta con normas constitucionales que se refieran en particular a la protección de los derechos de los consumidores y usuarios.

La ley No 17.250, del 11 de agosto de 2000, se ocupa de las relaciones de consumo y de la defensa del consumidor y la ley No 18.507, del 26 de junio de 2009 crea un procedimiento judicial especial en pequeñas causas para los reclamos de menor cuantía de los consumidores.

Cabe señalar que la ley No 17.250 está destinada a regir exclusivamente a las relaciones de consumo que se configuran dentro de los límites de la República.

Es importante tener presente que el Proyecto de Ley General de Derecho Internacional Privado, aprobado por la Cámara de Representantes el 7 de septiembre de 2016, que se encuentra pendiente de sanción en la Cámara de Senadores, contiene disposiciones específicas sobre jurisdicción competente y ley aplicable a los contratos de consumo (10).

(9) La ley No 5393 sobre Derecho aplicable a los Contratos Internacionales, en vigor desde el 21 de enero de 2015, excluye expresamente de su ámbito de aplicación a los contratos internacionales de consumo (artículo 1).

(10) El artículo 50 inciso 5 del texto aprobado por la Cámara de Representantes dispone: "Los contratos otorgados en relaciones de consumo se rigen: a) Por la ley del Estado donde los bienes se adquieren o los servicios se utilizan por parte del consumidor. b) En caso de que los bienes se adquieran o los servicios se utilicen en más de un país o no pudiere por otras circunstancias determinarse dicha ley, se regirán de conformidad por la ley del lugar del domicilio del consumidor. c) En los contratos celebrados a distancia, así como cuando la celebración ha sido precedida de ofertas o publicidad especifica en el domicilio del consumidor, se aplicará la ley de este Estado, siempre que el consumidor hubiere prestado su consentimiento en él". En materia de jurisdicción, el artículo 59 inciso D, determina la competencia internacional de los jueces de la República, "en materia de relaciones de consumo, si el consumidor es el demandante en tanto en la República se hubiere celebrado el contrato; o se hubiere efectuado en la República la prestación del servicio o la entrega de los bienes objeto de la relación de consumo". Se encuentra prohibida la prórroga de jurisdicción para estos supuestos (artículo 60 inciso 2). Puede verse el texto completo en: https://legislativo.parlamento.gub. uy/temporales/9920642.PDF [Fecha de consulta: 16/02/2019]. 


\section{e) Venezuela (11)}

La Constitución Bolivariana de Venezuela de 1999 alude en varias disposiciones a los derechos de los consumidores (artículos 113, 117, 281).

En el plano legal, el 4 de mayo de 2004, la Asamblea Legislativa aprobó la Ley de Protección al Consumidor y al Usuario. Sin embargo, fue sustituida por la Ley DEPABIS, del 1 de febrero de 2010, que a su vez fue abrogada por la Ley Orgánica de Precios Justos, publicada el 23 de enero de 2014. De esta manera, "en Venezuela, el consumidor no cuenta más con una ley específica de protección, habiendo el país retrocedido hasta la etapa previa a la edición de la primera ley de protección al consumidor" (Klein Vieira, 2017, p. 230).

A su turno, la Ley venezolana de Derecho Internacional Privado de 1998 no contiene disposiciones especiales sobre los contratos de consumo.

\section{Las normas Mercosur en la materia}

\section{IV.1. Normas de derecho derivado}

La protección de los consumidores en el Mercosur nace en el ámbito del Grupo de Mercado Común (GMC), más específicamente del Sub Grupo No 10 de Coordinación de Políticas Económicas que contaba con la Comisión de Estudios sobre Derecho del Consumidor. Esta Comisión compuesta por ministros de los Ministerios de Economía, de Relaciones Exteriores y de Justicia fue instituida en 1993 y se transformó en Comité Técnico (CT No 7) de la Comisión de Comercio (CCM) en 1994.

En esos primeros años del Mercosur, el Grupo Mercado Común aprobó una serie de resoluciones para proteger indirectamente a los consumidores en temas como salud, metrología y seguridad de los productos (Res. 31/92, 19/93, 31/93, 46/93, 82/93, 83/93, 91/93, 55/94, 56/94 y 64/94) (Rojo, 2012, p. 4).

A partir de la creación del Comité Técnico No 7 de "Defensa del consumidor", al que se le encomendó la misión fundamental de elaborar un proyecto de Reglamento del consumidor para el Mercosur, se empezaron a aprobar una serie de normas de derecho derivado especialmente destinadas a la protección

(11) Al momento de realizar este trabajo (febrero de 2019), la República Bolivariana de Venezuela se encuentra suspendida por tiempo indefinido del Mercosur por la "ruptura del orden democrático" en los términos del Protocolo de Ushuaia sobre Compromiso Democrático de 1998 (Decisión del 5 de agosto de 2017). 
del consumidor: resoluciones GMC No 126/94, 123/96, 124/96, 125/96, 126/96, $127 / 96,48 / 98$ y $21 / 2004$.

En efecto, en 1994 el Grupo Mercado Común emitió la Resolución 126/94 por la cual dispuso que hasta tanto no sea aprobado un Reglamento Común para la Defensa del Consumidor, cada Estado parte aplicará su propia legislación tuitiva del consumidor a los productos y servicios que se comercialicen en su territorio. Pero dejando a salvo que en ningún caso se podrá imponer a los bienes provenientes de los Estados partes exigencias superiores a las que se aplica a los productos y servicios oriundos de terceros países.

La Resolución 124/96 establece una declaración de los derechos básicos de los consumidores. En concreto, enumera ocho derechos: 1) a la protección de la vida, la salud y la seguridad contra los riesgos causados por las prácticas en el suministro de productos y servicios considerados peligrosos o nocivos; 2) a la educación y divulgación sobre el consumo adecuado de los productos y servicios, quedando garantizadas la libertad de elegir y el tratamiento igualitario cuando contrate; 3) a la información suficiente y veraz sobre los distintos productos y servicios; 4) a la protección contra la publicidad engañosa, métodos comerciales coercitivos o desleales, en el suministro de productos y servicios, conforme a los conceptos que se establezcan en los capítulos correspondientes del reglamento común sobre defensa del consumidor; 5) a la efectiva prevención y resarcimiento de los daños patrimoniales y morales, respecto de los derechos individuales y colectivos o de los intereses difusos; 6) al acceso a organismos judiciales y administrativos para la prevención y el resarcimiento de los daños patrimoniales y morales, respecto de los derechos individuales y colectivos o de los intereses difusos, mediante procedimientos ágiles y eficaces, garantizándose la protección jurídica, administrativa y técnica de los necesitados; 7) a la asociación en organizaciones cuyo objeto específico sea la defensa del consumidor y a ser representado por ellas; 8) a la adecuada y eficaz prestación de los servicios públicos en general, por proveedores públicos o privados.

A su turno, la resolución No 125/96 fija las pautas concretas tendientes a lograr una efectiva protección de la salud y seguridad de los consumidores. En tanto que la resolución No 126/96 establece los distintos parámetros a los cuales deberá adecuarse la publicidad de los bienes y servicios destinados al consumo a los efectos de no ser considerada abusiva o engañosa.

A su vez, la resolución No 127/1996 sobre garantía contractual fue sustituida por la resolución No 42/1998 en la misma materia. En lo sustancial, establece que cuando el proveedor de productos y servicios ofrezca garantía, deberá extenderla por escrito, estandarizada para productos idénticos, en el idioma del país de consumo, español o portugués, sin perjuicio que, además de estos, puedan utilizarse 
otros idiomas, debiendo ser de fácil comprensión, con letra clara y legible, e informar al consumidor sobre el alcance de los aspectos más significativos de la misma. No se requiere forma preestablecida para la garantía.

Por su parte, en diciembre de 2000 los presidentes de los Estados partes del bloque, reunidos en Florianópolis, emitieron una Declaración de Derechos Fundamentales de los Consumidores del Mercosur, comprometiéndose a una armonización progresiva de sus legislaciones en este aspecto.

En 2004, el GMC aprobó la resolución № 21/2004 que, a fin de favorecer la confianza en las relaciones de consumo realizadas por comercio electrónico a través de Internet, prescribe que debe garantizarse a los consumidores durante todo el proceso de la transacción comercial, el derecho a la información clara, precisa, suficiente y de fácil acceso sobre el proveedor del producto o servicio; sobre el producto o servicio ofertado; y respecto a las transacciones electrónicas involucradas. Dicha resolución se aplicará a todo proveedor radicado o establecido en alguno de los Estados Partes del Mercosur (artículo 1º).

En el año 2006, el Grupo Mercado Común aprobó la resolución No 45/2006 sobre publicidad engañosa que dispone que toda publicidad debe ser transmitida y divulgada de tal forma que el consumidor inmediatamente la identifique como tal, independientemente del medio de comunicación utilizado. Además, prohíbe expresamente toda publicidad engañosa entendida esta como cualquier modalidad de información, difusión o comunicación de carácter publicitario que sea entera o parcialmente falsa, o que de cualquier otro modo, inclusive por omisión de sus datos esenciales, sea capaz de inducir a error a los consumidores de cualquiera de los países, cuando la provisión de información refiera a la naturaleza, características, calidad, cantidad, propiedades, origen, precio, condiciones de comercialización o cualquier otro dato esencial sobre productos y servicios que sean necesarios para decidir una relación de consumo.

En 2010, fue aprobada por el mismo órgano la resolución No 1/2010 sobre protección de la salud y la seguridad de consumidores y usuarios (aspectos operativos), que en lo principal establece la obligación de los proveedores de productos o servicios que, posteriormente a la introducción de los mismos en el mercado de consumo, tengan conocimiento de su peligrosidad o nocividad, de comunicar inmediatamente tal circunstancia a las autoridades nacionales competentes del país que se trate y a los consumidores y usuarios del mismo, mediante anuncios publicitarios, sin perjuicio de otras medidas que cada Estado Parte pueda determinar.

En el año 2011, el GMC aprobó una nueva norma estableciendo conceptos básicos en materia de defensa del consumidor: la resolución № 34/2011, que viene a sustituir a la resolución No 123/96. Dispone definiciones aplicables a las relaciones 
de consumo en los Estados Partes: consumidor, proveedor, relación de consumo, producto, servicio, deber de información, oferta vinculante.

A los fines de este trabajo, nos interesa reproducir los primeros tres conceptos enumerados.

De acuerdo con la mencionada resolución, "consumidor" es toda persona física o jurídica que adquiere o utiliza productos o servicios en forma gratuita u onerosa como destinatario final, en una relación de consumo o como consecuencia o en función de ella. No se considera consumidor aquel que sin constituirse en destinatario final adquiere, almacena, utiliza o consume productos o servicios con el fin de integrarlos como insumo directo a otros productos o servicios en proceso de producción, transformación, comercialización o prestación a terceros.

Por su parte, proveedor es considerado toda persona física o jurídica, nacional o extranjera, privada o pública, y en este último caso estatal o no estatal, así como los entes despersonalizados de la Administración Pública de los Estados partes, que desarrolle de manera profesional, aun ocasionalmente, actividades de fabricación, producción, montaje, creación, construcción, transformación, importación, distribución y/o comercialización de productos y/o servicios.

En tanto que relación de consumo es el vínculo jurídico que se establece entre el proveedor que provee un producto o presta un servicio y el consumidor, quien lo adquiere o utiliza como destinatario final.

\section{IV.2. Normas convencionales}

A nivel de la fuente convencional del Mercosur fueron aprobados en el seno del Consejo Mercado Común (CMC): el Protocolo de Santa María sobre Jurisdicción Internacional en materia de Relaciones de Consumo (Decisión 10/1996) y recientemente, el Acuerdo del Mercosur sobre Derecho Aplicable en materia de Contratos Internacionales de Consumo (Decisión 36/2017).

Seguidamente nos ocuparemos del análisis y situación actual de ambos textos.

\section{IV.3. El Protocolo de Santa María sobre Jurisdicción Internacional en Materia de Relaciones de Consumo}

En el ámbito del Mercosur debemos recordar que el Protocolo de Buenos Aires sobre Jurisdicción Internacional en materia contractual (Mercosur $\backslash \mathrm{CMC} \backslash \mathrm{DEC}$ № 1/94) excluye también de su ámbito de aplicación los contratos de venta al consumidor (artículo 2.6). 
Sin embargo, en diciembre de 1996, el Consejo Mercado Común suscribió el Protocolo de Santa María sobre Jurisdicción Internacional en Materia de Relaciones de Consumo (Decisión CMC No 10/96 del 22 de diciembre de 1996), fruto del trabajo de la Reunión de Ministros de Justicia. Este Protocolo fija el procedimiento y los tribunales competentes para entender en cuestiones controvertidas nacidas de las relaciones de consumo, cuando proveedor y consumidor tengan su domicilio en distintos Estados del Mercosur, o cuando teniendo domicilio en un mismo Estado la prestación característica de la relación de consumo tenga lugar en otro Estado parte.

Tal como nos recuerda Perugini:

(...) a medida que se avanzaba en el estudio y elaboración del Protocolo de Buenos Aires se advertía la necesidad de dedicarle un instrumento independiente al de consumo. Varias fueron las razones por las que se decidió desagregarlo del Protocolo de Buenos Aires. La diferencia de posiciones frente a la autonomía, el tratamiento diferenciado entre el consumidor y su contraparte, la necesidad de adecuar el proceso para proteger al consumidor, por ejemplo. Por otra parte, tratar cada jurisdicción separadamente permitía concluir antes el Protocolo y otorgar al Mercosur en no más de dos años un instrumento útil a sus objetivos de armonización (2005, p. 49).

El Protocolo de Santa María sobre Jurisdicción Internacional en Materia de Relaciones de Consumo contiene una regla general en materia de jurisdicción, indicando en el artículo 4 que "tendrán jurisdicción internacional en las demandas entabladas por el consumidor, que versen sobre relaciones de consumo los jueces o tribunales del Estado en cuyo territorio esté domiciliado el consumidor". A su turno, el proveedor de bienes o servicios podrá demandar al consumidor ante el juez o tribunal del domicilio de este.

El artículo 5 brinda otras opciones excepcionales, a disposición exclusiva del consumidor, manifestada expresamente en el momento de entablar la demanda, el Estado: a) los jueces del lugar de celebración del contrato; b) los jueces del lugar de cumplimiento de la prestación del servicio o de la entrega de los bienes; o c) los jueces del lugar del domicilio del demandado. Finalmente, a tenor del artículo 6, si el demandado tuviere domicilio en un Estado Parte y en otro Estado Parte filial, sucursal, agencia o cualquier otra especie de representación con la cual realizó las operaciones que generaron el conflicto, el actor podrá demandar en cualquiera de dichos Estados.

El Protocolo de Santa María no contempla la posibilidad de acordar un foro jurisdiccional para que dirima una controversia de consumo. 
En cambio, en la Unión Europea, el reglamento (UE) No 1215/2012, que sustituyó a partir del 10 de enero de 2015 al reglamento No 44/2001, relativo a la competencia judicial, el reconocimiento y la ejecución de resoluciones judiciales en materia civil y mercantil, en lo que concierne a los acuerdos de elección de foro en los contratos de consumo, prevé que solo serán válidos si son celebrados con posterioridad al nacimiento de la disputa, o sin tan solo aumentan los tribunales ante los cuales puede demandar el consumidor a su contraparte, o cuando atribuyan competencia a los jueces del Estado miembro en el cual estuvieren domiciliadas o residan con habitualidad ambas partes al momento de celebrar el contrato, siempre que la ley de ese país no los prohíba.

En defecto de acuerdo válido de elección de foro, el Reglamento de la UE, a diferencia de nuestro Protocolo de Santa María distingue dos supuestos.

El consumidor solo goza de protección si el profesional ejerce actividades comerciales o profesionales en el Estado miembro en cuyo territorio tenga domicilio el consumidor (criterio Doing Businees o Mercado natural del empresario) $\mathrm{o}$, alternativamente, por cualquier medio, dirige estas actividades hacia dicho Estado miembro (criterio Stream-of-Commerce o Mercado de conquista)(12). Una demanda interpuesta por un consumidor puede serlo ante el tribunal del Estado miembro en el territorio donde se encuentra el demandado o ante el tribunal del Estado miembro donde el consumidor tenga su domicilio. En caso de que un profesional promoviera una acción contra un consumidor, esta solo podría hacerse ante los tribunales de los Estados miembros en cuyo territorio esté domiciliado el consumidor(13).

En cambio, cuando es el consumidor quien se desplaza al país donde opera normalmente el empresario (consumidor activo), no se aplica la protección del artículo 15. El consumidor, entonces, no podrá demandar en el país de su domicilio, ya que el empresario no penetró en su mercado.

(12) Sobre el artículo 15.1.c), la doctrina sostiene que es una "norma de transacción", que trata de proteger y de impulsar el e-commerce Business - to - Consumer (Calvo Caravaca y Carrascosa González, 2001, p. 102).

(13) Si bien las normas se mantienen muy semejantes a las contenidas en el Convenio de Bruselas, el ámbito de aplicación ha sido modificado significativamente. No es más necesario haber realizado todos los actos tendientes a la contratación desde su domicilio, sino que será suficiente que el cocontratante haya desarrollado su actividad en el Estado donde reside el consumidor, o la haya dirigido hacia allí, siempre que el contrato celebrado se encuentre dentro del marco de dicha actividad. La eliminación en el artículo 15 del Reglamento del requisito exigido en el artículo 13 del Convenio de Bruselas relativo a que el consumidor hubiere realizado en el Estado de su domicilio los actos necesarios para la celebración del contrato, está vinculada a la dificultad para localizar esos actos en la contratación electrónica (De Miguel Asensio, 2001, p. 443). 
Ahora bien, hasta la fecha el Protocolo de Santa María no ha podido entrar en vigor, ya que su propio artículo 18 dispone expresamente que la tramitación para su aprobación en el ámbito de cada uno de los Estados partes, con las adecuaciones que fueren necesarias, solo podrá iniciarse después de la aprobación del "Reglamento Común Mercosur para la Defensa del Consumidor en su totalidad, incluidos sus anexos, si los tuviere, por el Consejo del Mercado Común". Es decir, que autoexcluye su aplicación y la supedita a la aprobación de dicho Reglamento, que con el correr de las negociaciones posteriores, se transformó en un tratado o protocolo, que cobró forma a través del Acuerdo sobre derecho aplicable en materia de contratos internacionales de consumo, aprobado por el Consejo Mercado Común en diciembre de 2017.

De todos modos, cabe señalar que en la Opinión Consultiva № 1 de 2007, el Tribunal Permanente de Revisión del Mercosur (TPR) deja asentada la posibilidad de aplicar el Protocolo de Santa María, aun cuando no se encuentre vigente, pero en calidad de soft law:

Asimismo, cabe consignar que precisamente el PSM (Protocolo de Santa María) de relaciones de consumo a la fecha no internalizado por ningún Estado parte, solamente puede ser invocado como un marco referencial doctrinario o como soft law dado que aún no se encuentra en vigor.

\section{IV.4. El nuevo acuerdo del Mercosur sobre derecho aplicable en materia de contratos internacionales de consumo}

El camino para alcanzar este Acuerdo fue largo y sinuoso, y comenzó a poco de haberse aprobado el Protocolo de Santa María.

Así, en las reuniones celebradas entre el 25 al 29 de noviembre de 1997 fue presentado por el Comité Técnico No 7 un Proyecto de "Protocolo de Defensa del Consumidor del Mercosur". En términos generales, el texto referido, fijaba pautas máximas y unificadas de protección al consumidor en los cuatro socios originarios del bloque.

A fines de 1997, el CT No 7 había logrado consensuar una versión definitiva del proyecto con la finalidad de ser elevado a la CCM para su tratamiento y aprobación, en la inteligencia que la labor no había acabado aún, pero se había logrado una norma básica donde se plasmaron las coincidencias a las que se había arribado. Cabe advertir que ahora la propuesta ya no era un "Reglamento", como se previó en un principio, sino un "Protocolo" (derecho convencional), y 
que consecuentemente una vez depositados los instrumentos de ratificación fuera considerado parte del Tratado de Asunción (Klein Viera, 2017, p. 171).

Sin embargo, Brasil rechazó la suscripción del proyecto argumentando que no podían tolerar que el mencionado instrumento implique una disminución en los niveles de protección que su legislación interna garantiza a sus consumidores. Ante esta circunstancia, durante la XXV Reunión de la Comisión de Comercio del Mercosur, realizada en Montevideo, en los días 9 y 10 de diciembre de 1997, el Protocolo fue rechazado.

Algunos años después nuevamente se pondría sobre la mesa de negociaciones el tema. En efecto, el Programa de Acción 2000 dispuso como objetivo prioritario del CT No 7 "Concluir e implementar el Reglamento Común de Defensa del Consumidor, marco que deberá garantizar los derechos del consumidor en el espacio económico ampliado, sin constituir obstáculos innecesarios al comercio".

Además, la Decisión 64/2000 del CMC que aprueba el Estatuto de la Ciudadanía del Mercosur contempla expresamente la creación de un Sistema Mercosur de Defensa del Consumidor, compuesto por: un sistema Mercosur de Información de Defensa del Consumidor; una acción regional de capacitación (Escuela Mercosur de Defensa del Consumidor) y una norma Mercosur aplicable a contratos internacionales de consumo.

En este contexto y con base en la Propuesta de Brasil presentada en la Séptima Conferencia Especializada de Derecho Internacional Privado (CIDIP VII) en el marco de la OEA, en agosto de 2010 en Río de Janeiro, la delegación brasileña presentó un Proyecto de Resolución del GMC sobre derecho aplicable a los contratos internacionales de consumo en la LXIII Reunión Ordinaria del CT № 7.

Con posterioridad, luego de algunas revisiones, fue presentado un nuevo borrador en la CXXII Reunión Ordinaria de la CCM, celebrada el 22 de septiembre de 2011, ahora como Proyecto de Acuerdo sobre derecho aplicable en materia de contratos internacionales de consumo.

En la LXXXIX Reunión Ordinaria del GMC, celebrada en octubre de 2012, en Cuiabá, fue aprobado el Proyecto de Decisión 15/2012, que contenía el mencionado Acuerdo.

Sin embargo, durante varios años la propuesta, en sus distintas revisiones, no pasó por el Consejo Mercado Común para su definitiva aprobación.

Fue finalmente el 21 de diciembre de 2017 cuando el Consejo Mercado Común aprobó el "Acuerdo sobre Derecho Aplicable en Materia de Contratos Internacionales de Consumo" (Mercosur/CMC/DEC. № 36/17), con nuevas modificaciones, 
que requerirá al menos la ratificación de dos Estados parte para su entrada en vigor.

El texto aprobado se compone tan solo de 10 artículos distribuidos en los siguientes capítulos: Primero: Definiciones y ámbito de aplicación; Segundo: Derecho aplicable; Tercero: Disposiciones generales.

El fundamento de la norma es buscar "dar protección al consumidor y adoptar reglas comunes sobre el derecho aplicable en materia de contratos internacionales de consumo, contratos entre proveedores de bienes o prestadores de servicios y consumidores o usuarios en la región".

A su turno, el objetivo del Acuerdo es determinar el derecho aplicable(14) en materia de contratos internacionales de consumo celebrados en cualquiera de los estados del Mercosur, entre consumidores y proveedores de otros estados partes. Por lo tanto, no comprende a los proveedores de estados no integrantes del Mercosur.

El Acuerdo exceptúa de su ámbito de aplicación a: a) los contratos comerciales internacionales entre proveedores profesionales de bienes y servicios; $b$ ) las cuestiones derivadas del estado civil de las personas y la capacidad de las partes; c) las obligaciones contractuales que tuviesen como objeto principal cuestiones sucesorias, testamentarias, regímenes matrimoniales o aquellas derivadas de relaciones de familia; d) los acuerdos sobre arbitraje o elección de foro y las cuestiones de jurisdicción; e) las cuestiones de derecho de sociedades, de seguridad social, tributarias, laborales, sobre nombres de dominio; f) los negocios jurídicos sobre los fallidos y sus acreedores y demás procedimientos semejantes, especialmente los concordatos y análogos.

También están exceptuados los demás contratos y relaciones de consumo y las obligaciones de ellos resultantes que, incluyendo consumidores, se encuentren regulados por convenciones internacionales específicas en vigor.

El artículo 2 del Acuerdo define como consumidor a toda persona física o jurídica que adquiere o utiliza productos o servicios en forma gratuita u onerosa como destinatario final, en una relación de consumo o como consecuencia o en función de ella.

(14) Si bien las normas aluden a "derecho aplicable" y no a "ley aplicable", debe entenderse que el Acuerdo excluye al llamado soft law, quedando limitada la elección entre leyes estatales (Klein Vieira, 2015, p. 64). 
En cambio, excluye del concepto de consumidor a aquel que, sin constituirse en destinatario final, adquiere, almacena, utiliza o consume productos o servicios con el fin de integrarlos como insumo directo, a otros productos o servicios en proceso de producción, transformación, comercialización o prestación a terceros.

Nos encontramos con una calificación de consumidor amplia dado que abarca no solamente a la persona física o humana, sino también a la persona jurídica y al consumidor por equiparación (bystander (15)) (Klein Vieira, 2016).

En tanto que considera como proveedor a toda persona física o jurídica, nacional o extranjera, privada o pública y en este último caso, estatal o no estatal, así como los entes descentralizados de la Administración Pública de los Estados Partes, que desarrolle de manera profesional, aún ocasionalmente, actividades de fabricación, producción, montaje, creación, construcción, transformación, importación, distribución y/o comercialización de productos y/o servicios (artículo 2).

Como podemos observar, estas definiciones coinciden con las adoptadas en la Resolución GMC No 34/2011. Pero el acuerdo añade algunos otros conceptos necesarios.

En tal sentido, califica contrato internacional como aquel en el que el consumidor tiene su domicilio, al momento de la celebración del contrato, en un Estado Parte diferente del domicilio o sede del proveedor profesional que intervino en la transacción o contrato.

Según este acuerdo, se considerará como lugar de celebración, en los contratos de consumo a distancia, al "domicilio del consumidor", mientras que si el contrato no es a distancia "se entiende por lugar de celebración el lugar donde el consumidor y el proveedor se encontraren físicamente para la celebración del contrato".

Por su parte, el domicilio del consumidor es el "informado al proveedor profesional de productos o servicios, al momento de celebrarse el contrato entre las partes".

Los artículos 4 y 5 son centrales, ya que se ocupan de determinar el derecho aplicable a los contratos celebrados en el estado de su domicilio, y cuando se celebran fuera de este. Una versión preliminar se refería a este último supuesto como el turista y visitante.

(15) El consumidor bystander, equiparado o por equiparación, o expuesto es aquel que, sin haber celebrado un contrato con el proveedor de bienes o servicios, sufren un perjuicio por la utilización de los mismos, derivado de su exposición a la relación de consumo. 
En el primer caso, los contratos internacionales celebrados estando el consumidor en el Estado Parte de su domicilio, especialmente en caso de contratación a distancia, se rigen por el derecho elegido por las partes, quienes pueden optar por el derecho del domicilio del consumidor, del lugar de celebración o cumplimiento del contrato o de la sede del proveedor de los productos o servicios. El derecho elegido será aplicable siempre que fuera más favorable al consumidor.

En el segundo caso, es decir, cuando los contratos internacionales de consumo son celebrados por el consumidor estando este fuera del Estado parte de su domicilio, se rigen por el derecho elegido por las partes, quienes pueden optar válidamente por el derecho del lugar de celebración o de cumplimiento del contrato o por el del domicilio del consumidor. El derecho elegido también será aplicable siempre que fuera más favorable al consumidor.

En este último supuesto, el legislador del Mercosur eliminó la opción a favor del lugar de la sede del proveedor de los productos o servicios.

Podemos apreciar que el acuerdo sigue la tendencia predominante en la materia, que consiste en admitir la autonomía de la voluntad, pero limitada y en tanto la elección del derecho aplicable resulte en beneficio del consumidor. Es decir, la elección debe recaer en algunas de las leyes alternativas que menciona la norma de forma taxativa a modo de catálogo.

Así lo ha destacado la doctrina:

(...) la fórmula conveniente no implica evitar la autonomía de la voluntad de forma radical; de lo que se trata es de impedir que la elección de un derecho que lleve a la inaplicabilidad de normas imperativas que resultarían de aplicación si esa elección no procede. Es decir, no tendría por qué haber problema alguno en que se aplique un derecho u otro siempre que se resguarden los criterios de protección de la ley normalmente aplicable que se reflejan en sus normas materiales imperativas que deben considerarse como tales en la relación internacional. Por otra parte, en una u otra hipótesis, las normas de conflicto aplicables pueden ser orientadas materialmente hacia la protección del consumidor (Dreyzin de Klor, 2014, p. 16).

A nuestro parecer, la disposición del Mercosur conduce a una mejor solución en relación con nuestra fuente interna que se limita a prohibir tajantemente la autonomía de la voluntad, incluso en desmedro de un derecho elegido más favorable al consumidor en el caso concreto.

Evidentemente la orientación material que contiene la norma Mercosur es una de las principales virtudes del Acuerdo. 
Ahora bien, para el caso en el que las partes no hayan ejercido la autonomía de la voluntad, se aplicará: 1) el derecho del domicilio del consumidor en el caso de la contratación internacional a distancia cuando el consumidor está en el país de su domicilio, y 2) el lugar de celebración para el caso de contratación internacional cuando el consumidor está fuera de su estado de domicilio.

Es sencillo de apreciar cómo el legislador del Mercosur optó por la ya clásica diferenciación en la materia, entre consumidor pasivo y activo. Si bien en ambos casos, se prioriza la autonomía de la voluntad de las partes, y rige el principio de aplicación de la ley más favorable al consumidor, existe una importante distinción respecto a los criterios subsidiarios adoptados. Mientras que el consumidor pasivo, en su beneficio, goza de la protección de la ley de su domicilio, en el caso del consumidor activo, resulta aplicable la ley del lugar de celebración del contrato.

Similar distinción hace nuestro artículo 2655 CCiv. y Com., pero las soluciones del Acuerdo son más sencillas a la hora de su interpretación para encuadrar el caso concreto.

A su turno, el artículo 6 establece que la elección del derecho aplicable por las partes debe ser expresa y por escrito, conocida y consentida en cada caso. En caso de elección del derecho aplicable por el proveedor para obtener la adhesión del consumidor, el derecho elegido por este como aplicable debe estar expresado de forma clara tanto en las informaciones previas brindadas al consumidor, como en el contrato mismo.

Por su parte, en caso de contratación en línea (online), la elección del derecho aplicable debe estar expresada en forma clara y destacada en todas las informaciones brindadas al consumidor.

No es un dato menor que el Acuerdo se haya puesto a la altura de la realidad actual de la contratación internacional de consumo, que en muchas ocasiones se celebra a través de medios electrónicos.

El Acuerdo se ocupa en particular de los contratos de viaje y turismo, y del tiempo compartido.

Respecto a los primeros, la norma hace una excepción expresa a las reglas establecidas en los artículos 4 y 5 , al regular que en los contratos de viaje cuyo cumplimiento tenga lugar fuera del Estado Parte del domicilio del consumidor, contratados en paquete o con servicios combinados, como grupo turístico o juntamente con otros servicios de hotelería y/o turismo, serán regulados por el derecho del domicilio del consumidor. 
Es pasible de crítica la limitación de opciones otorgadas al consumidor por los artículos previos, en el caso del consumidor turista que, aún ante la existencia de una ley relacionada más favorable, siempre se lo someterá al derecho de su domicilio.

Por otro lado, en una de las versiones anteriores se exigía que el domicilio del consumidor coincidiese con el lugar de sede o filial de la agencia de viajes u organizador del paquete turístico o con el lugar donde se realizó la oferta. El texto definitivo, es superador de estos borradores preliminares, dado que ofrece una protección más amplia a favor del turista.

Finalmente, el artículo 8 sobre tiempo compartido establece que las normas imperativas del Estado Parte donde fue realizada la oferta, publicidad o cualquier actividad de mercadeo (marketing), entre otras actividades realizadas por los representantes o por los propietarios, organizadores o administradores de tiempos compartidos y de sistemas semejantes o contratos de utilización por turno de bienes inmuebles o la suscripción de precontratos o contratos de tiempo compartido o derechos de uso por turno de bienes inmuebles, serán considerados para la interpretación del contrato, la cual será efectuada en favor del consumidor. Es decir, que tales normas imperativas no se imponen, sino que meramente deberán ser tenidas en cuenta a los fines de la interpretación del contrato, y en todo caso siempre priorizará los derechos del usuario.

Cabe señalar que en las versiones anteriores del proyecto de Acuerdo se incluían disposiciones sobre la aplicación de normas internacionalmente imperativas del foro, que debían aplicarse siempre a favor del consumidor, así como también una cláusula de orden público internacional como limitación a la aplicación de un derecho extranjero, ya sea elegido por las partes, como aquel impuesto por la norma de conflicto en defecto de elección.

De todos modos, estos límites a la aplicación del derecho extranjero son ampliamente reconocidos por la legislación, la jurisprudencia y la doctrina de nuestros países y su omisión en el Acuerdo no será óbice para considerarlos si se presentan a la hora de resolver una controversia en concreto.

Tampoco se incluyeron en la versión aprobada normas sobre cooperación jurídica internacional, pese a que en borradores que circularon durante las negociaciones previas se exigía la designación de una Autoridad Central por Estado Miembro.

No obstante, el Mercosur cuenta con normas vigentes sobre cooperación que resultan complementarias a las del Acuerdo. Principalmente, nos referimos a las del Protocolo de Las Leñas de Cooperación y Asistencia Jurisdiccional en materia 
Civil, Comercial, Laboral y Administrativa, así como a las del Protocolo de Ouro Preto de Medidas Cautelares.

\section{A modo de colofón}

Los derechos de consumidores y usuarios han sido reconocidos por el legislador nacional y provincial y, en especial, por la propia Constitución de numerosos Estados Americanos, entre ellos la República Argentina que los garantiza desde la reforma de 1994 en su artículo 42.

Estos derechos llamados de tercera generación tienen por loable finalidad proteger a los consumidores, procurando restablecer el equilibrio entre una relación desigual como es la que se configura entre aquellos que consumen bienes y productos o utilizan servicios y quienes se los proveen.

Si bien es una realidad vigente desde muchos siglos que prácticamente todas las personas, en mayor o menor medida, son consumidores, en la actualidad, con la proliferación de los medios electrónicos, la reducción de las distancias y la irrupción del comercio electrónico B2C, las relaciones de consumo han adquirido nuevas características y en especial, se han internacionalizado a gran escala.

Es, por ello, que el Derecho Internacional Privado y el Derecho de la Integración no pueden permanecer ajenos a esta realidad. Por el contrario, deben asumir su rol de herramienta indispensable para proveer a los consumidores, usuarios, turistas, ciber consumidores de un marco jurídico transparente y confiable que les brinde un alto grado de certidumbre respecto de la ley que resultará aplicable así como del juez que será competente en caso que surja una controversia, así como mecanismos alternativos de resolución de disputas eficaces y rápidos que les permitan resolver todo tipo de conflicto que se suscite en torno de la relación de consumo.

Tal como vimos a lo largo de este trabajo, el Mercosur ha dado un gran paso con la aprobación del Acuerdo sobre Derecho Aplicable en materia de contratos internacionales de Consumo. También lo ha hecho nuestro país con la inclusión de normas específicas en el Código Civil y Comercial de la Nación.

Los Estados parte del Mercosur deben asumir, ahora, el compromiso internacional de ratificar dicho Acuerdo, así como destrabar la entrada en vigor del Protocolo de Santa María. Seguidamente, nuestros jueces deberán interpretar y aplicar satisfactoriamente las nuevas disposiciones en favor de los derechos de los consumidores. 
Quedan, entonces, varios pasos para dar en este extenso camino y muchos desafíos por encarar a nivel regional.

\section{Bibliografía}

Arias de Rincón, M. I. (2005). La protección al consumidor en el comercio electrónico. Revista Derecho y Tecnología (pp. 53-71).

Calvo Caravaca, A. y Carrascosa González, J. (2001). Conflictos de leyes y conflictos de jurisdicciones en Internet. Madrid: Colex.

De Miguel Asensio, P. A. (2001). Derecho Privado de Internet. Madrid: Civitas.

Dreyzin de Klor, A. (2007). El derecho aplicable al comercio electrónico: un tema que interesa a los consumidores, a la CIDIP y a otros foros de codificación. En: D. Fernández Arroyo y J. A. Moreno Rodríguez (coords.), Protección de los consumidores en América: trabajos de la CIDIP VII (OEA) (pp. 239-258). Asunción: CEDEP/La Ley Paraguay.

Dreyzin de Klor, A. (2012). Los derechos del consumidor: Visión internacional. Una mirada interna. Buenos Aires: Zavalía.

Dreyzin de Klor, A. (2014). El derecho internacional privado y las relaciones consumo. Revista de la Facultad. Nueva Serie II (pp. 13-54).

Fernández Arroyo, D. y Moreno Rodríguez, J. A. (coords.) (2007). Protección de los consumidores en América: trabajos de la CIDIP VII (OEA). Asunción: CEDEP/ La Ley Paraguay.

Garro, A. y Zuppi, A. (1990). Compraventa Internacional de Mercaderías. Buenos Aires: La Rocca.

González Martín, N. (2005). Comercio electrónico y protección del consumidor: acercamiento al contexto mexicano. En A. Calvo Caravaca y S. Areal Ludeña (dir.), Cuestiones Actuales del Derecho Mercantil Internacional (pp. 615-632). Madrid: Colex.

Guillemard, S. (2004). Le cyberconsommateur est mort, vive l'ahérent. Journal du Droit International N. I (janvier - fevrier - mars). Juris Classeur (pp. 7-61).

Iud, C. (2006). Mecanismos de protección al consumidor ante un acuerdo de prórroga de jurisdicción. Suplemento de Derecho Internacional Privado y de la Integración (elDial.com) número 21. Recuperado de https://www.eldial.com/nuevo/suple-privado_ant2.asp?mes=6\&anio=2006 [Fecha de consulta: 16/02/2019]. 
Iud, C. (2015). Contratos internacionales en el Código Civil y Comercial argentino 2014. Anuario Argentino de Derecho Internacional número XXIV (pp. 227-228).

Jayme, E. (1995). Identité culturelle et intégration: Le droit internationale privé postmoderne. Recueil des Cours de l'Académie de Droit International de la Haye, vol. (251) (pp. 33-269).

Klein Vieira, L. (2013). Protección internacional del consumidor. Procesos de escasa cuantía transfronterizos. Buenos Aires - Montevideo: BdeF.

Klein Vieira, L. (2015). El Proyecto de Acuerdo del Mercosur sobre Derecho aplicable en materia de contratos de consumo. Revista de Direito du Consumidor. 24, No 99 (pp. 159-184).

Klein Vieira, L. (2016). El concepto de consumidor y el Mercosur ampliado. Un análisis del derecho de fuente convencional e interna de los Estados partes del bloque. Revista de Direito do Consumidor, vol. (107) (pp. 169-196).

Klein Vieira, L. (2017). La hipervulnerabilidad del consumidor transfronterizo y la función material del Derecho Internacional Privado. Buenos Aires: Departamento de Publicaciones (Facultad de Derecho - UBA) / La Ley.

Lima Marques, C. (1999). Direitos do consumidor no Mercosul: algunas sugestoes frente ao impasse. Jurisprudencia Argentina, vol. (1999-III) (pp. 912-934).

Lima Marques, C. (2001). La insuficiente protección del consumidor en las normas del Derecho Internacional Privado - De la necesidad de una Convención Interamericana (CIDIP) sobre la ley aplicable a algunos contratos y relaciones de consumo. Curso de Derecho Internacional. CJI/OEA. Recuperado de http://www. oas.org/dil/agreementspdf/cidipvii_home_temas_cidip-vii_proteccionalconsumidor_leyaplicable_apoyo_propuestabrasil.pdf. [Fecha de consulta: 16/02/2019].

Lima Marques, C. (2004). Confiança no Comércio Eletrônico e a Proteção do Consumidor (um estudo dos negócios jurídicos de consumo no comércio eletrônico). São Paulo: Editora Revista dos Tribunais.

Lima Marques, C. (2012). Comercio electrónico de consumo internacional: modelos de aplicación de la ley más favorable al consumidor y del foro más conveniente. En: A. Dreyzin de Klor (dir.), Los derechos del consumidor: Visión internacional. Una mirada interna (pp. 127-156). Buenos Aires: Zavalía.

Lorenzetti, R. (1996). La relación de consumo: conceptualización dogmática en base al derecho del área regional Mercosur. Revista Jurídica La Ley (T. E) (pp. 1303-1320). 
Najurieta, M. S. (1991). Conflicto de Jurisdicciones en caso que involucran a Consumidores. Revista de Derecho Comercial y de las Obligaciones, T A, año 24 (pp. 139-141).

Perugini Zanetti, A. (2005). Derecho Internacional Privado del Consumidor. Rosario: XVIII Congreso Ordinario de la Asociación Argentina de Derecho Internacional.

Pocar, F. (1984). La protection de la partie faible en droit international privé. Collected Courses of the Hague Academy of International Law, The Hague Academy of International Law, Vol. (188) (pp. 339- 418).

Rojo, M. (2012). La defensa del consumidor en el Mercosur. Aequitas Revista de la Facultad de Ciencias Jurídicas de la Universidad de Salvador, número (6). Recuperado de https://p3.usal.edu.ar/index.php/aequitas/article/viewFile/1685/2135 [Fecha de consulta: 16/02/2019].

Schötz, G. J. (2003). Los acuerdos de jurisdicción en contratos de consumo internacionales celebrados en Internet. Revista del Derecho Comercial y de las Obligaciones, vol. (188) (36) (pp. 5-23).

Scotti, L. (2007). La (des)protección de ciberconsumidor en América (Una mirada desde la Argentina y el Mercosur). En: D. Fernández Arroyo y J. A. Moreno Rodríguez (coords.), Protección de los consumidores en América: trabajos de la CIDIP VII (OEA) (pp. 519-546). Asunción: CEDEP/La Ley Paraguay.

Scotti, L. (2017). Manual de Derecho Internacional Privado. Buenos Aires: La Ley.

Soto, A. M. (2015). El derecho del consumidor frente al fenómeno de la globalización y la internacionalidad: perspectivas generales. La 'lex mercatoria' y el derecho del consumidor. Las normas de derecho internacional privado. En G. Stiglitz (dir.), Tratado de derecho del consumidor (pp. 39-62). Buenos Aires: Thomson Reuters La Ley.

Stiglitz, G. A. (1995). El derecho del consumidor en Argentina y en el Mercosur. Revista Jurídica La Ley, tomo B (pp. 1361-1374).

Toniollo, J. A. (1998). La protección internacional del consumidor: reflexiones desde la perspectiva del derecho internacional privado argentino. Revista de Derecho Internacional del Mercosur, vol. (1998.6) (pp. 94-117).

Uriondo de Martinoli, A. (2017). El consumidor internacional. Suplemento especial XVI Jornadas de Derecho Civil, Jurisprudencia Argentina, volumen (2017III) (pp. 1453-1467). 
Uzal, M. E. (1991). La Protección del consumidor en el Derecho Internacional Privado. Revista del Derecho Comercial y de las Obligaciones, 24, T. A (pp. 254-255).

Uzal, M. E. (2006). La protección al consumidor en ámbito internacional: La ley aplicable y la jurisdicción competente. En M. E. Uzal (coord.), Relaciones de consumo, derecho y economía (pp. 161-216). Buenos Aires: La Ley.

\section{Legislación}

Constitución de la República Argentina. Boletín Oficial de la República Argentina, Buenos Aires, 23/08/1994.

Constitución de la República Federativa de Brasil. Diário Oficial da União D.O.U. 05/10/1988.

Constitución de la República de Paraguay. Gaceta Oficial, 22/06/1992.

Constitución de la República Oriental del Uruguay. Constitución de 1967 con las modificaciones plebiscitadas el 26 de noviembre de 1989, el 26 de noviembre de 1994 y el 8 de diciembre de 1996.

Constitución Bolivariana de Venezuela. Gaceta Oficial, 19/02/2009.

Ley No 24.240/93 Boletín Oficial de la República Argentina, Buenos Aires, $4 / 2008$.

Ley No 26.993, Boletín Oficial de la República Argentina, Buenos Aires, 19/9/14.

Ley No 26.994, Boletín Oficial de la República Argentina, Buenos Aires, 10/10/14.

Brasil

Ley No 8.078/90, D.O.U., 12/09/1990.

Ley No 12.376, D.O.U., 09/09/1942.

Ley No 13.105, D.O.U., 13/03/2015.

Paraguay

Ley No 1.334/98, Gaceta Oficial, 30/10/1998.

Ley No 4868, Gaceta Oficial, 01/03/2013. 
Ley No 5393, Gaceta Oficial, 20/01/2015.

Decreto No 21.004, Gaceta Oficial, 02/05/2003.

\section{Uruguay}

Ley No 17.250/00, Diario Oficial, 17/08/2000.

Ley No 18.507, Diario Oficial, 17/08/2000.

Ley No 17.250, Diario Oficial, 07/07/2009.

Proyecto de Ley General de Derecho Internacional Privado, aprobado por la Cámara de Representantes el 7 de septiembre de 2016 (pendiente de aprobación en la Cámara de Senadores).

\section{Venezuela}

Ley DEPABIS (Ley para la Defensa de las Personas en el acceso para los bienes y los servicios), Gaceta Oficial, 01/02/2010. Derogada por decreto No 600 .

Ley Orgánica de Precios Justos (decreto No 600), Gaceta Oficial, 23/01/2014.

Ley de Derecho Internacional Privado, Gaceta Oficial, 06/08/1998.

\section{Tratados internacionales}

Tratados de Derecho Civil Internacional de Montevideo de 1889 y de 1940.

Convención de las Naciones Unidas sobre los Contratos de Compraventa Internacional de Mercaderías (1980). Viena.

Convención sobre la Ley Aplicable a la Compraventa Internacional de Mercaderías (no vigente) (1985). La Haya.

CIDIP V (1994) sobre Derecho Aplicable a los Contratos Internacionales, México.

Convención de las Naciones Unidas sobre la Utilización de las Comunicaciones Electrónicas en los Contratos Internacionales (2005). Nueva York.

Protocolo sobre Jurisdicción Internacional en materia de Relaciones de Consumo (1996). Santa María.

Acuerdo del Mercosur sobre Derecho Aplicable en materia de Contratos Internacionales de Consumo (2017). Brasilia. 
Mercosur

Decisión CMC No 10/1996, Protocolo de Santa María sobre Jurisdicción Internacional en materia de Relaciones de Consumo.

Decisión CMC No 36/2017, Acuerdo del Mercosur sobre Derecho Aplicable en materia de Contratos Internacionales de Consumo.

Resolución GMC № 126/94.

Resolución GMC № 123/96, derogada por Resolución GMC № 34/2011.

Resolución GMC No 124/96.

Resolución GMC No 125/96.

Resolución GMC No 126/96.

Resolución GMC No 42/1998.

Resolución GMC No 21/2004.

Resolución GMC No 45/2006.

Resolución GMC No 1/2010.

Resolución GMC No 34/2011.

Declaración presidencial de Derechos Fundamentales de los Consumidores del Mercosur, Florianópolis, 15 de diciembre de 2000.

\section{Otros instrumentos consultados}

Reglamento (CE) 593/2008, Parlamento Europeo y del Consejo, de 17 de junio de 2008, sobre la ley aplicable a las obligaciones contractuales (Roma I).

Declaración de Sofía sobre los Principios Internacionales de Protección al Consumidor, septuagésima quinta Conferencia de la Asociación de Derecho Internacional, Bulgaria, 26 - 30 de agosto de 2012.

Directrices de las Naciones Unidas para la Protección del Consumidor, Asamblea General en su resolución 39/248, 16 de abril de 1985, ampliadas posteriormente por el Consejo Económico y Social en su resolución 1999/7, 26 de julio de 1999, y revisadas y aprobadas por la Asamblea General en su resolución 70/186, 22 de diciembre de 2015. 
Tribunal Permanente de Revisión del Mercosur, Opinión Consultiva № 01/2007: "Norte S.A. Imp. Exp. c/ Laboratorios Northia Sociedad Anónima, Comercial, Industrial, Financiera, Inmobiliaria y Agropecuaria s/ Indemnización de Daños y Perjuicios y Lucro Cesante", solicitud cursada por la Corte Suprema de Justicia del Paraguay con relación a los autos del Juzgado de Primera Instancia en lo Civil y Comercial del Primer Turno de la jurisdicción de Asunción.

Fecha de recepción: 17-02-2019 Fecha de aceptación: 24-06-2019 
